employ a known principle as to friction in his famous submarine telegraph relay; he was the discoverer of the principle. The same may be said about the description of Brown's mechanical relay. We think that Prof. Boys is occasionally misled by assuming that his own very intimate knowledge of phenomena is shared by other people.

J. P.

\section{MATHEMATICAL TEXT-BOOKS.}

(1) Subjects for Mathematical Essays. By Dr. C. Davison. Pp. $\mathrm{x}+\mathrm{I} 60$. (London: Macmillan and Co., Ltd., I9I5.) Price $3 s .6 d$.

(2) Junior Algebra. By A. G. Cracknell and A. Barraclough. Pp. vi $+28 \mathrm{o}$. (London : University Tutorial Press, Ltd., I9r5.) Price 2s. $6 d$.

(3) Papers Set in the Qualifying Examination for the Mechanical Sciences Tripos, 1906-1913. Pp. 9o. (Cambridge : At the University Press, 1914.) Price $2 s$, net.

(4) A Shilling Arithmetic. By W. M. Baker and A. A. Bourne. Pp. xiv + 192. (London: G. Bell and Sons, Ltd., I9I 5.)

(5) Practical Mathematics Second Year. By A. E. Young. Pp. $x i+r 64$. (London: G. Routledge and Sons, Ltd., r9r5.) Price 2s. net. (6) The Laws of Algebra. An Elementary Course in Algebraic Theory. By A. G. Cracknell. Pp. vi +68 . (London: University Tutorial Press, Ltd., 19I5.) Price Is.

(I) THIS collection of essays will be found of 1 the greatest value in the training of mathematical scholarship candidates. Such work as this enables a student to coordinate his knowledge, and so consolidates the material that is floating vaguely about his mind, when he has completed the various courses of reading prescribed for him. It is indeed mainly by essay work that he begins to see the bearing of one subject on another and to appreciate the help which can be derived from the interfusion of subjects. We do not therefore recommend the use of this book merely because it will stand the candidate in good stead for examination purposes, but because we believe that the greater breadth of outlook essay work produces is of real educational value to him, and because it plays a part in his mental development which no other form of exercise can achieve.

(2) This course takes the reader as far as quadratic equations, and the two final chapters deal with indices and logarithms. In addition to illustrative examples, there is a considerable amount of explanatory matter. The former is

No. 2386, VOL. 95] essential, but it is open to question whether junior students can profitably read the discussions which text-books often contain : for example, on page 70 we find "Related Unknowns.-One of the chief uses of algebra is that of solving problems where it would be either difficult or impossible to solve them by arithmetic. The method is to represent the unknown quantities by letters, then to express the problem as an equation and to solve this equation." In our view, such passages as these merely overload the book and assist neither the pupil nor the teacher. There are no particularly original features, but the examples are well arranged and provide a sensible elementary course.

(3) The reprint in a cheap and compact form of papers set in the Mathematical and Engineering Triposes at Cambridge is of real service to a large circle of students. The general character of the papers is evidence of the recent changes in mathematical teaching. Those engaged in the higher work in secondary schools will find here much that will enrich their weekly problem papers. The questions are both practical and stimulating.

(4) This small volume includes all the arithmetic that in our view ordinary students require and some things, such as true discount or inverse compound interest, they should omit. If the general education is to include, as we believe it ought, trigonometry, practical mechanics and, if possible, the ideas of the calculus, it is essential that arithmetic should be merely a means to an end, a preparation for other work rather than a subject in itself. It is the comparatively slight dimensions of this text-book that constitute its chief claim to favourable consideration.

(5) The author has already published a course of practical mathematics for first year technical students: this volume contains the subject matter of the second year course. In this volume, as in the first, there is a first-rate set of examples, and we have no hesitation in recommending it for extensive use.

(6) This discussion of the meaning and validity of the fundamental laws of algebra is intended for senior divisions of secondary schools. It includes rational and irrational numbers, and rational indices, but excludes imaginaries, infinities, limits, and irrational indices. The language is throughout simple and the argument is set out clearly, but we are doubtful whether the author's partition is satisfactory. The theory of limits has now assumed so prominent a place in modern analysis that it is hard to refuse to admit it into the school curriculum, and it seems wise therefore to take it in conjunction with any substantial discussion of irrational numbers. 